\title{
When and why performance goals predict exploitation behaviors: An achievement goal complex analysis of the selection function of assessment
}

\author{
Nicolas Sommet ${ }^{1} \cdot$ David Nguyen $^{2,4} \cdot$ Kevin Fahrni $^{2} \cdot$ Martin Jobin $^{2} \cdot$ Ha-Phong Nguyen ${ }^{2} \cdot$ Hamza Sehaqui $^{2}$. \\ Fabrizio Butera ${ }^{3}$
}

(c) Springer Science+Business Media, LLC, part of Springer Nature 2018

\begin{abstract}
We adopted an achievement goal complex framework (studying achievement goals and reasons connected to goals) to determine when and why performance goals predict exploitation of others' knowledge. We hypothesized that: (i) when selective assessment is used (exams aiming to select a limited number of individuals), the link between performance goals and exploitation orientation is stronger; (ii) the reason why is that selective assessment fosters performance goals regulated by controlled reasons. Study $1(N=166)$ supported these hypotheses in a "real world" environment, comparing students enrolled in programs using non-selective versus selective assessment (but having a majority of common courses). Then, an experimental causal-chain-like design was used. In Study $2(N=187)$, presenting an intelligence test as selective (vs. [self-] evaluative) predicted controlled reasons connected to performance goals. In Study $3(N=192)$, inducing performance goals using controlling (vs. autonomy-supportive) language predicted exploitation orientation, indirectly impairing informationsharing behaviors. The results contribute to the understanding of both the structural antecedents and interpersonal consequences of achievement goal complexes.
\end{abstract}

Keywords Achievement goals · Self-determination theory $\cdot$ Achievement goal complex $\cdot$ Exploitation orientation .

Selective assessment

Kevin Fahrni, Martin Jobin, Ha-Phong Nguyen and Hamza Sehaqui have contributed equally to this work.

Electronic supplementary material The online version of this article (https://doi.org/10.1007/s11031-018-9742-y) contains supplementary material, which is available to authorized users.

Nicolas Sommet

nicolas.sommet@unil.ch

1 Life Course and Inequality Research Centre (LINES), University of Lausanne, Bâtiment Géopolis, Bureau \#5785, Quartier UNIL-Mouline, 1015 Lausanne, Switzerland

2 Swiss Federal Institute of Technology in Lausanne, Lausanne, Switzerland

3 Laboratoire de Psychologie Sociale (UNILaPS), University of Lausanne, Lausanne, Switzerland

4 Laboratoire d'Optique Biomédicale (LOB), Swiss Federal Institute of Technology in Lausanne, Lausanne, Switzerland
I've been used many times over by classmates who only called when they needed help; they didn't associate with me once the class was over.

An interviewee recounting his/her experience as a pre-med student (Coombs 1998, p. 3).

Imagine two students pursuing similar performance goals (i.e., the aim to outperform others), but for different reasons. The first student is a pre-med student aiming to outperform others out of an institutional pressure, whereas the second student is a first-year math student aiming to outperform others out of a personal challenge. Which of these two students is more likely to be a "cut-throat," namely a student striving to succeed at all cost, even if it means exploiting others' knowledge?

The present set of studies is an attempt to answer such a query. We raise the two-fold question of when and why performance goals lead students to exploit others. First, we argue that performance goals endorsed in an environment 
using highly selective assessment (i.e., whose purpose is to select a limited number of individuals) eventuate in a higher exploitation orientation toward information exchange (answering the when question). Second, we argue that this is because selective assessment alters the reasons connected to performance goals (answering the why question).

In addressing this issue, we rely on the newly developed achievement goal complex framework, allowing the study of both the strength of achievement goals and the reasons connected to the goals (for an early conceptualization, see Elliot and Thrash 2001; for recent reviews, see Senko 2016; Vansteenkiste et al. 2014b). Using this framework, we offer insights into the selective function of assessment and the motivational underpinning of exploitation behaviors.

\section{Performance goals and exploitation orientation}

Achievement goals are self-regulatory commitments that direct individuals' responses in competence-relevant contexts (Elliot 1999). The two most studied achievement goals are performance and mastery goals, crossed by the approachavoidance distinction. Performance-approach goals focus on outperforming others, whereas performance-avoidance goals focus on not being outperformed by others. Masteryapproach goals focus on mastering a task and improving over time, whereas mastery-avoidance goals focus on not falling short of mastering a task or declining over time. In the present research, only performance- and mastery-approach goals are considered (and referred to as performance and mastery goals, respectively).

The strength of performance goals is a predictor of poorly communal interpersonal behaviors (Conroy et al. 2009). Because performance-oriented individuals perceive others' competence as threatening, they tend to display hostile, standoffish, and antisocial interpersonal behaviors (Sommet et al. 2015). When interacting with an exchange partner (i.e., a potential source of information), performance goal-oriented individuals are more likely to disregard the interactant (Sommet et al. 2014), show low level of openness in information giving (Poortvliet et al. 2007), and employ deception and ethically-questionable tactics so as to exploit other's knowledge (Kilduff et al. 2016; for additional empirical evidence, see Toma et al. 2013).

At a psychological level, individuals pursuing performance goals tend to perceive others as "rivals" rather than "supports" (Ryan and Pintrich 1997). Thus, it is not surprising that performance goals are a positive predictor of an exploitation orientation towards information exchange (Poortvliet et al. 2009b, Study 2). Exploitation orientation is the tendency to provide an exchange partner as little valuable information as possible, while expecting the most of his/ her information. Exploitation orientation differs from help orientation in that the individual tends to give low-quality information to the other and-at the same time-expects to receive high-quality information (Poortvliet et al. 2007). Importantly, an increase in exploitation orientation is one of the key mechanisms through which performance goals impair interpersonal behaviors (for a review, see Darnon et al. 2012). Simply put, performance goals prompt exploitation orientation, which in turn drives individuals to tactically deceive others or withhold information from them (compared to a mastery goal and a no-goal experimental condition; Poortvliet et al. 2007, Study 1).

However, the relation between the strength of performance goals and exploitation behaviors varies from one study to another (for a systematic review, see Senko et al. 2011, pp. 35-36). For instance, scholars reported null effects of performance goals on cooperative preferences (Elliot et al. 2016), attitudes toward help-giving behaviors (Poortvliet and Darnon 2014, Study 3), and prosocial orientation, including sharing behaviors (Cheung et al. 1998). Two studies even revealed that performance goals were positively associated with self-reported quality of peer relationships (Liem et al. 2008) and social intimacy goals (i.e., working with others to develop friendship; Nelson and DeBacker 2008). Thus, performance goals may not always entail an exploitation orientation. We suggest herein that taking into account the reasons connected to performance goals may afford better prediction of outcomes.

\section{Controlled reasons connected to performance goals and exploitation orientation}

Although there are different ways to conceptualize the reasons connected to performance goals (e.g., need for achievement and fear of failure, appearance and competitive concerns; Elliot and Church 1997; Urdan and Mestas 2006), self-determination theory (SDT) has so far generated the most influential empirical work (for a review, see Vansteenkiste et al. 2014b). Self-determination theorists argued that the subjective meaning (i.e., the functional significance) attributed to a goal is contingent upon the reasons to which it is connected (Deci and Ryan 1985). Similar goals may have different meanings, depending on whether individuals regulate them using autonomous or controlled reasons (for a review, see Deci and Ryan 2000). An achievement goal regulated by autonomous reasons is enacted with a sense of self-endorsement, ownership, and volition. For instance, an individual pursuing a performance goal regulated by autonomous reasons would strive to outperform others because s/he views this goal as meaningful or inherently satisfying. However, an achievement 
goal regulated by controlled reasons is enacted through operationally separable reasons. For instance, an individual pursuing a performance goal regulated by controlled reasons would strive to outperform others because s/he views this goal as a way to meet others' demands or selfimposed contingencies (for the first empirical work using this conceptualization, see Vansteenkiste et al. 2010a).

It has long been suspected that, relative to autonomous reasons, controlled reasons connected to goals increase the intensity of frustration and setbacks encountered during task performance (Sheldon and Elliot 1998). Empirical evidence indicates that controlled reasons involve more pressure during achievement goal striving (Özdemir Oz et al. 2015) and an appraisal of goal difficulty as a threat to self-worth rather than a challenge (Ntoumanis et al. 2014). More specifically, controlled reasons connected to performance goals were found to predict detrimental experiential outcomes, such as low vitality, negative affect, or anxiety (Gillet et al. 2015, Study 2; Vansteenkiste et al. 2010a, b). Importantly, in this line of research, controlled reasons connected to performance goals predicted variance in the outcomes above and beyond the strength of performance goals per se (i.e., while statistically controlling for "mere" performance goals; for a review, see Vansteenkiste et al. 2014b, pp. 162-165).

Although most achievement situations are embedded in social contexts, achievement goal complex scholars have so far almost exclusively studied intrapersonal outcomes. Yet Vansteenkiste et al. (2014b) argued that controlled reasons connected with achievement goals may also yield an interpersonal cost, "as others would be more likely to be perceived as instrumental to meeting one's preferences or as obstacles to be removed" (p. 162). In the case of performance goals, controlled reasons may reinforce the perceptions that others are a threat to self-competence, thereby leading performance-oriented individuals to dodge others, to belittle them, or to try to surpass at any price. The small amount of research on this topic seems to be consistent with such an idea: Controlled reasons connected to performance goals increase help-avoidance (Senko and Tropiano 2016), objectifying attitudes (perceiving others as barriers that need to be surpassed by whatever means necessary; Vansteenkiste et al. 2010a, Study 2), as well as cheating attitudes and behaviors (copying off another student; Vansteenkiste et al. 2010b, Study 2). Importantly, in the three studies above, the effects of autonomous reasons connected to performance goals were not statistically different from zero (except on cheating, for which the effect was negative). It is then possible to expect a similar pattern for exploitation orientation, namely that controlled (but not autonomous) reasons connected to performance goals should be a positive predictor of exploitation orientation, above and beyond the strength of performance goals.
An important remaining question pertains to the conditions under which performance goals are connected to controlled reasons. In the following section, we argue that the use of selective assessment creates an external incentive to outperform others, thereby promoting the endorsement of performance goals regulated by controlled reasons.

\section{Selective assessment and controlled reasons connected to performance goals}

Selective assessment aims to choose a limited number of individuals who are given access to scarce resources (e.g., the best students who will be entitled to proceed to the next semester and/or obtain their diploma; Sommet et al. 2013). Research showed that the use of selective assessment is widespread in the academic domain. We know, for instance, that departments facing an excess of demand over supply tend to use harder grading practices (De Paola 2011), that two-third of the American law departments admit the use of grade standardization (Kaufman 1994), and that the tertiary graduation rate in developed countries is no more than $40 \%$ (OECD 2013). Such assessment practices serve the selective function of higher education, that is, comparing, selecting, and orienting students toward different positions in society (Autin et al. 2015; Darnon et al. 2009; for pioneering research on the role of "filter" fulfilled by higher education institutions, see Bourdieu and Passeron 1970).

Given its very nature, selective assessment conveys the impression that the likelihood of one to be selected decreases as that of others increases, making the aim to outperform others more relevant. This is consistent with social interdependence theory (see Johnson et al. 2014): At a psychological level, selective assessment makes people perceive selfand other-competence as being negatively correlated (one candidate's success is seen as another's failure), bringing them to evaluate their competence based on an other-referenced standard (i.e., to be focused on approaching normative competence). A study comparing departments using highly versus moderately selective assessment revealed that thirdyear undergraduates enrolled in the first kind of department perceived more peer competition and reported more performance goals (Sommet et al. 2015). Consistently, experimental studies revealed that social comparison feedback (Shin et al. 2017), anticipation of normative evaluation (Pekrun et al. 2014), and even the mere salience of the selection function of university (Jury et al. 2017, Study 1), predicted a stronger endorsement of performance goals.

However, in this research, we shift the focus from selective assessment as a predictor of the mere directional function of achievement motivation (what individuals want to achieve; in our case, outperforming others) to selective assessment as a predictor of the energizational function of 
achievement motivation (why individual want to achieve; that is, the reasons connected to performance goals). In environments using external motivators, individuals are more likely to pursue goals regulated by controlled reasons (Reeve and Assor 2011). For instance, in contexts involving external evaluation procedures or competition, individuals tend to regulate their goals using contingent self-esteem or reward, failing to fully internalize them (Deci and Ryan 2016). More specifically, high-stakes testing approaches such as selective assessment practices have been described as rewarding outcomes rather than behaviors, thereby inducing a shift in the perceived locus of causality for goals from internal to external (Ryan and Brown 2005; for early experimental evidence, see Deci et al. 1981). As selective assessment practices involve incentivizing relative performance, it is legitimate to think that the performance goals they promote are primarily regulated by controlled reasons. Simply put, in the context of selective assessment, individuals are likely to endorse the goal to rank among the best students out of institutional pressure. However, in the context of non-selective assessment, some individuals may also endorse the goal to outrank others, but less out of institutional pressure (e.g., for self-grounded reasons). This is consistent with recent findings showing that when the function of selection performed by the university is made salient, individuals tend to endorse performance goals for more instrumental reasons, namely as a practical means to succeed within the higher education system (i.e., social utility reasons; Jury et al. 2017, Study 2).

\section{Hypotheses and overview}

To summarize, the reviewed literature suggests that (i) controlled reasons connected to performance goals should predict exploitation orientation, and (ii) in the context of selective assessment, performance goals should be regulated by more controlled reasons. We can, therefore, infer the following general hypothesis:

General hypothesis. When selective (vs. non-selective) assessment is used, performance goals act as a stronger predictor of exploitation orientation; this interactive effect is mediated by a stronger relationship between performance goals and controlled reasons.

Three studies were conducted. Study 1 tested the general hypothesis in a "real world" environment. In Study 1, selective assessment was a natural group variable. Students from two programs were sampled: In the first program, assessment merely served a self-evaluative function (i.e., to make students more aware of their level of knowledge), whereas in the second program, assessment served a selective function (i.e., to select the students who will be admitted to university). Study 1 had high ecological validity, but nonrandomized sampling posed a threat to internal validity: In the preparatory program serving a selective function, assessment was not explicitly based on relative performance, selfselection could have played a role (differences between the students choosing each program), and confounding variables could have influenced the results (differences between the programs not related to assessment). Building up from Study 1 , we therefore conducted two experiments. We drew on the so-called experimental causal-chain design to ascertain the causal role of the key variables (Spencer et al. 2005). The General Hypothesis was split into two sub-hypotheses:

Sub-hypothesis 1. When selective (vs. non-selective) assessment is used, performance goals are more positively associated with controlled reasons.

Sub-hypothesis 2. Controlled reasons connected to performance goals are a positive predictor of exploitation orientation.

Study 2 tested Sub-Hypothesis 1 by experimentally inducing the moderating variable, that is, selective assessment. Study 3 tested Sub-Hypothesis 2 by experimentally inducing the mediating variable, that is, controlled reasons connected to performance goals. The overall model and study organization are presented graphically in Fig. 1.

Mastery goals were measured and statistically controlled in Studies 1-2. Moreover, the reasons connected to mastery goals were included in Study 2 to ensure that the observed effect was specific to performance goals. Autonomous reasons connected to performance were included in all studies, but no predictions were formulated (we neither expected the relationship between performance goals and autonomous reasons to depend on the use of selective assessment, nor autonomous reasons to predict exploitation orientation). Study 1 used a convenience sample, whereas sample sizes of Studies 2 and 3 were determined a priori. Power analyses revealed that between about 130 and 160 participants were needed to detect medium size effects $(f=.25)$ with a power of .80. We oversampled to make sure that we exceeded our target sample size after excluding missing data. All data exclusions, variables analyzed, and inductions are reported. Questionnaires, de-identified raw data, and Stata / SPSS syntax files for the three studies are available through FigShare (https://figshare.com/s/05c0aa4a5c78c2549040).

\section{Study 1: Testing the full model in a "real world" environment}

Study 1 aimed to test the General Hypothesis. Students from two different programs (yet, mostly similar in content) participated in the study: In the first program, students selfassessed their work, whereas in the second program, they had to prepare themselves for a highly selective final assessment. Performance goals were expected to be regulated by 


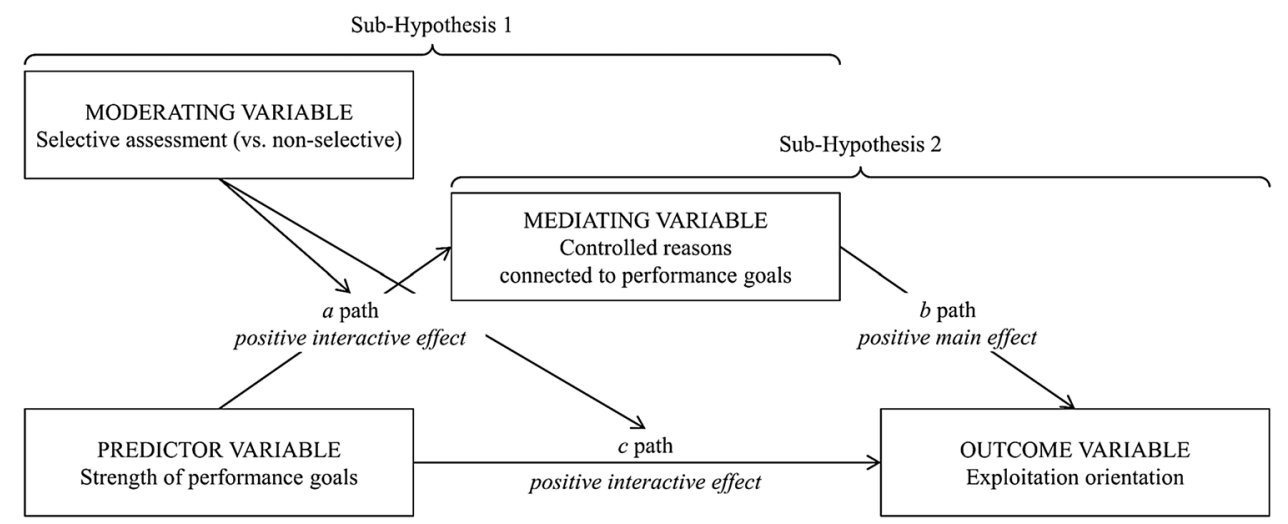

Fig. 1 The hypothesized moderated mediation model (General Hypothesis; tested in Study 1). The relationship between performance goals and controlled reasons connected to performance goals is expected to be more positive when selective assessment is used (Sub-

more controlled reasons in the second program, leading to a higher exploitation orientation.

\section{Method}

\section{Participants and procedure}

A total of 169 students were asked to fill in a paper-andpencil questionnaire on "academic motivation in preparatory programs" at the beginning of three parallel courses in the spring semester of 2013. Three respondents were excluded due to missing data. The final sample consisted of $N=166$ participants, 40 women and 117 men ( 9 unspecified), $M_{\text {age }}=20.31(S D=1.64)$.

Students could be enrolled in one of two preparatory programs offered by a high-ranking Swiss engineering and science university: "Polymath" $(n=81)$ or "CMS" (i.e., Special Mathematics Course; $n=85$ ). The two programs share a majority of common courses (four out of seven). Despite their academic similarity, they differ in their assessment policies.

On the one hand, Polymath uses self-referenced assessment. Students can choose to follow this program before entering university to upgrade their knowledge. Those who do so are responsible for the evaluation of their achievement at the end of each semester. They then proceed to the first year of university without any selection procedure. Thus, assessment does not fulfil a selective function: The assessment's objective is to help students to better understand their level of knowledge. Note that Polymath was cancelled in 2017.

On the other hand, CMS uses selective assessment. Students are required to follow this program before being permitted to enter the institution (e.g., holders of foreign or vocational high school diploma). Only those who pass
Hypothesis 1, experimentally tested in Study 2), and the relationship between controlled reasons connected to performance goals and exploitation orientation is expected to be positive (Sub-Hypothesis 2, experimentally tested in Study 2)

CMS's final examination are allowed to proceed to the first year of university. Thus, assessment fulfills a selective function: The assessment's objective is to select the students allowed to pursue their academic studies. On campus, CMS has a reputation of being a competitive environment, in which many are called, but few are chosen.

Participants did not significantly differ on sex and age across programs (see Supplementary Materials, upper part of Table S1).

\section{Variables}

Table 1 presents the descriptive statistics and correlation matrix. All self-report measures used a seven-point scale $(1=$ not at all, to $7=$ completely $){ }^{1}$

\section{Strength of achievement goals}

We extracted six items from Elliot and McGregor's (2001) Achievement Goal Questionnaire (for the French validation, see Darnon and Butera 2005). Three items measured performance goals (e.g., "It is important for me to do better than other students") and three others measured mastery goals (e.g., "I want to learn as much as possible from the classes").

\footnotetext{
${ }^{1}$ Study 1 was part of a student research project. For pedagogical reasons, students were encouraged to proposed their own ideas of variables to add to the questionnaire. Self-efficacy, social dominance goals, and reciprocity orientation (i.e., confidence that others will provide one with good information) were therefore additionally assessed. As these variables are not directly relevant to our research question, they are not included in the main analysis. For the sake of transparency, the variables are described in Supplementary Materials.
} 


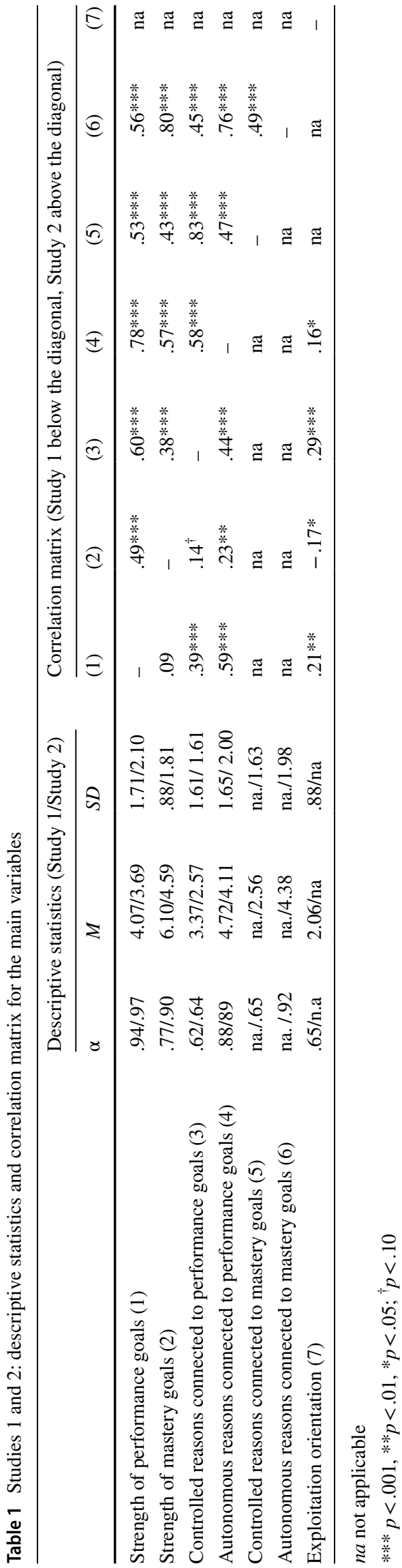

\section{Reasons connected to performance goals}

We used the four items from Vansteenkiste et al. (2010b). We only included these four items to keep the questionnaire as short as possible and not to interfere too much with classroom activities. Participants were asked to answer to these items "[i]n reference to the three questions previously posed [i.e., the performance goals items]." Two items measured controlled reasons connected to performance goals (e.g., "[I pursue such performance goals] because I would feel bad, guilty, or anxious if I didn't do so") and two others measured autonomous reasons connected to performance goals (e.g., "[I pursue such performance goals] because I find this a personally valuable goal"). ${ }^{2}$

\section{Exploitation orientation toward information exchange}

We used the five items from Poortvliet et al. (2009b). Two sample items are "[When working together with other students] I hope the others will not profit too much from my information" and "I don't care if the other receives poor information from me."

\section{Results}

\section{Preliminary analysis}

In a preliminary analysis, performance goals were regressed on preparatory program $(-0.5=$ Polymath [self-assessment] and $+0.5=C M S$ [selective assessment]). Consistent with prior research (Murayama and Elliot 2012), performance goals were stronger in the program using selective assessment, $B=0.55[0.03,1.07], p=.038, \eta_{\mathrm{p}}^{2}=.03$ (numbers in brackets represent $95 \%$ CIs). However, since we did not aim at testing the effect of preparatory program on the strength of performance goals, but on the reasons connected with performance goals, this result will not be commented. Note that multicollinearity between predictors (here, between preparatory program and performance goals) does not violate

\footnotetext{
${ }^{2}$ Different views were expressed regarding the conceptual status of this variable. Vansteenkiste et al. (2010a) initially conceived it as "underlying reasons of performance-approach goals" (p. 223; see also, Delrue et al. 2016; Vansteenkiste et al. 2014a; Michou et al. 2016). Recently, other scholars have challenged this position, arguing that the variable includes both a goal and a reason component and would be better conceived as an achievement goal complex (Sommet and Elliot 2017; see also Senko and Tropiano 2016). We designed and conducted this set of studies before this debate; here, we conceive the variable as pertaining to reasons connected to achievement goals, and we conceive an achievement goal complex as corresponding to an interaction between this variable and the strength of the achievement goal (as in Gaudreau 2012; Gaudreau and Braaten 2016).
} 
the assumption of regression and has only minimal impact, if any, on the estimation of the coefficients (Shieh 2010).

\section{Main analysis}

Table 2 presents the full set of results, and Fig. 2 presents a graphical representation of the full mediated moderation model.

\section{Overview of the mediated moderation analysis}

Linear regression analysis was conducted in two stages. First, we tested the interaction between preparatory program and performance goals on exploitation orientation. Second, mediated moderation analysis was carried out. This aimed to test whether the stronger association between performance goals and controlled reasons in the selective program could explain the moderation. Mastery goals and their interactions were controlled, and all predictors were mean-centered.

\section{Total effect on exploitation orientation}

Exploitation orientation was regressed on preparatory program $(-0.5=$ Polymath [self-assessment] and $+0.5=C M S$ [selective assessment]), performance goals, mastery goals, and all possible interactions. Consistent with General Hypothesis, the interaction between preparatory program and performance goals was significant, $B=0.16,] 0,0.32$ ], $p=.044, \eta_{\mathrm{p}}^{2}=.03$ (left reverse bracket indicates zero is excluded; $c$ path). Simple slope analysis revealed that performance goals were positively associated with exploitation orientation in the program using selective assessment, $B=0.18[0.07,0.28], p=.001, \eta_{\mathrm{p}}^{2}=.07$, but not in the program using self-assessment, $B=0.02[-0.10,0.13], p=.764$ (Fig. 3). However, performance goals were a positive predictor of exploitation orientation, whereas mastery goals were a negative predictor (a conceptual replication of Poortvliet et al. 2007, Study 2).

\section{Mediational role of controlled reasons connected to performance goals}

Effects on the mediating variables Controlled and autonomous reasons connected to performance goals were regressed on the same predictors as before. Consistent with Sub-Hypothesis 1 , the interaction between preparatory program and performance goals in predicting controlled reasons was significant, $B=0.27$ [0.01, 0.53], $p=.040, \eta_{\mathrm{p}}^{2}=.03$ ( $a 1$ path). Simple slope analysis revealed that performance goals were more positively associated with controlled reasons in the program using selective assessment, $B=0.45$ $[0.28,0.63], p<.001, \eta_{\mathrm{p}}^{2}=.14$, than in the program using self-assessment, $B=0.18$ [-0.01, 0.37], $p=.063, \eta_{\mathrm{p}}^{2}=.02$.

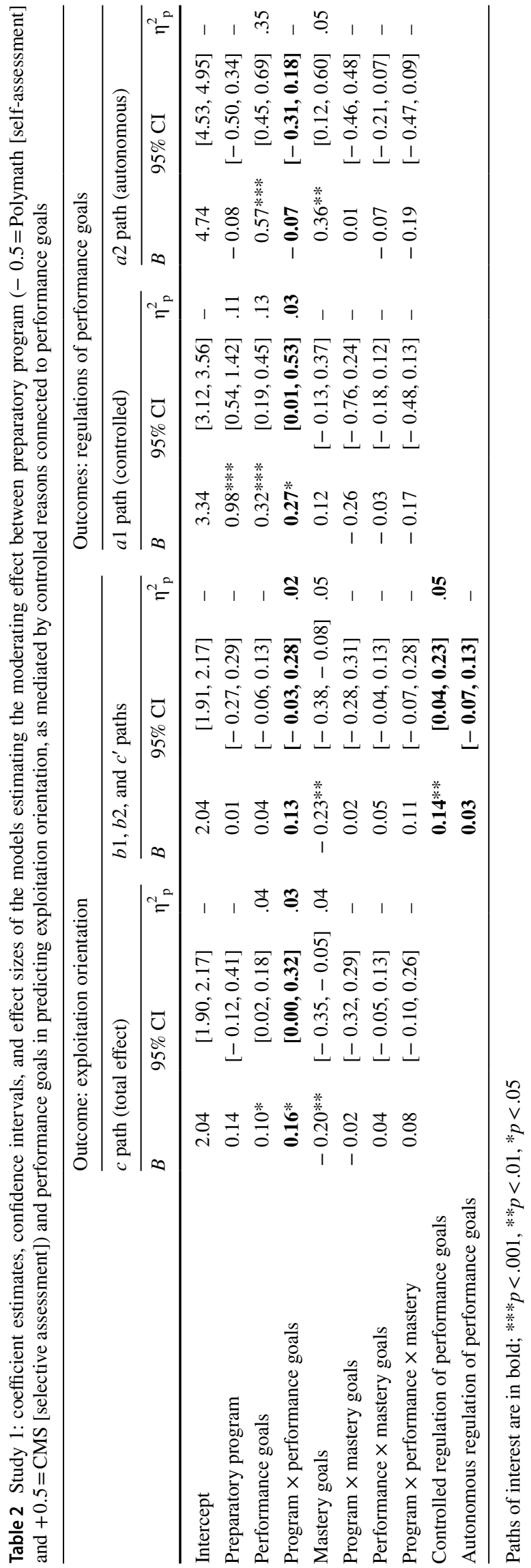


Fig. 2 Study 1: moderating effect between performance goals and preparatory program on exploitation orientation, as mediated by controlled reasons connected to performance goals. Notes: $* p<.05, * * p<.01$; the grey dotted arrows represent paths which are not significantly different from zero

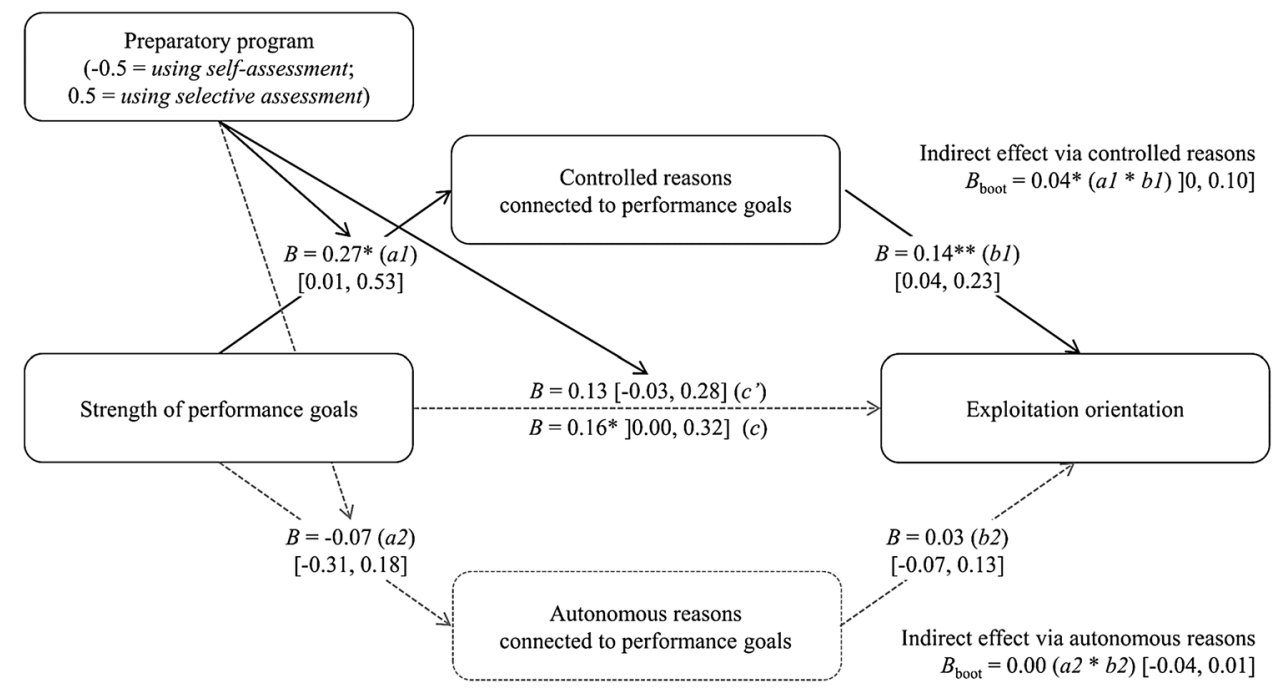

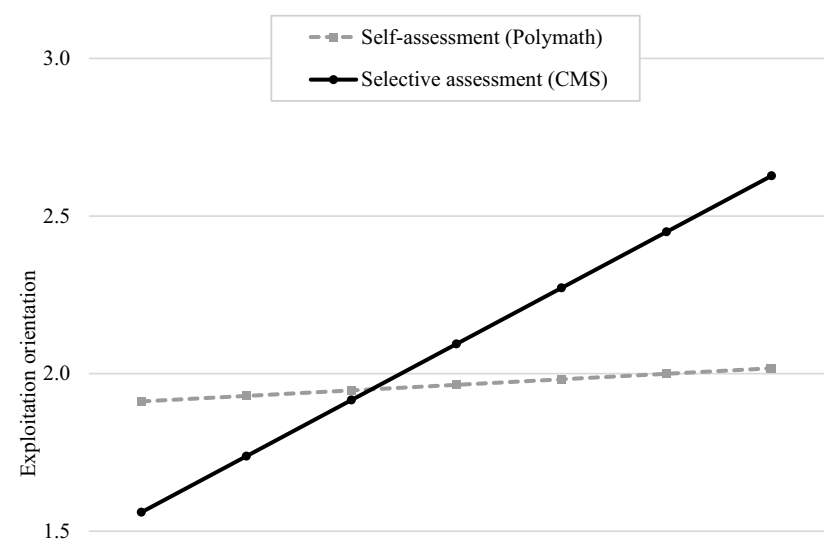

1.0

$\begin{array}{ccccccc}1 & 2 & 3 & 4 & 5 & 6 & 7 \\ & & \text { Strength of performance goals }\end{array}$

Fig. 3 Study 1: self-reported exploitation orientation, as a function of both performance goals and preparatory program in which the participant is enrolled

However, the interaction between preparatory program and performance goals in predicting autonomous reasons was not significant, $B=-0.07[-0.31,0.18], p=.595$ ( $a 2$ path).

Mediating, direct, and indirect effects Exploitation orientation was regressed on the same predictors as before, but this time including controlled and autonomous reasons connected to performance goals. Consistent with Sub-Hypothesis 2 , controlled reasons were a positive predictor, $B=0.14$ [0.04, 0.23], $p=.006, \eta_{\mathrm{p}}^{2}=.05$ (b1 path). Autonomous reasons were not a significant predictor, $B=0.03 \mathrm{CI}[-0.07$, 0.13 ], $p=.555$ ( $b 2$ path). At the same time, the interac- tion between preparatory program and performance goals became non-significant, $B=0.13[-0.03,0.28], p=.113$, $\eta_{\mathrm{p}}^{2}=.02$ ( $c^{\prime}$ path).

The indirect effects were estimated using the bias-corrected bootstrapping method with 50,000 resampling (see Rucker et al. 2011). The indirect effect of the interaction via controlled reasons was $\left.\left.B_{\text {boot }}=0.04\right] 0,0.10\right](a 1 \times b 1$ path $)$. Specifically, the conditional indirect effect of performance goals on exploitation orientation was positive in the program using selective assessment, $B_{\text {boot }}=0.06[0.02,0.12]$, but not in the program using self-assessment, $B_{\text {boot }}=0.02$ $[0,0.07]$. However, the indirect effect of the interaction via autonomous reasons was not significant, $B_{\text {boot }}=0.00$ $[-0.04,0.01]$.

\section{Discussion}

Consistent with our General Hypothesis, performance goals were a stronger predictor of exploitation orientation in the program using selective assessment. This interaction was explained by the fact that (i) performance goals were regulated by more controlled reasons in the program using selective assessment (Sub-Hypothesis 1), and that (ii) these controlled reasons specifically related to exploitation orientation, over and above the strength of performance goals (Sub-Hypothesis 2). These findings were specific to performance goals (mastery goals did not interact with the preparatory program in predicting outcomes) and controlled reasons (performance goals did not interact with the preparatory program in predicting autonomous reasons).

Two limitations of Study 1 should be acknowledged. First, one can argue that, in the program using selective assessment, performance goals could be associated with controlled reasons connected to any goals (not only performance goals). Study 2 addressed this issue by additionally 
measuring autonomous and controlled reasons connected to mastery goals. Second, we cannot establish the causal nature of our model. For instance, it is possible for the results to be explained by unanticipated differences between CMS and Polymath which would not be related to assessment (differences in terms of pressure, compulsoriness, etc). It is also possible that students initially oriented towards performance goals regulated by controlled reasons and/or exploitation chose to enter in a more competitive program (a self-selection hypothesis) rather than the students from the program using selective assessment progressively became more competitive (a socialization hypothesis). To address the issue of causality inference, we drew on the experimental causal-chain design (Spencer et al. 2005): In Study 2, we experimentally manipulated "selective assessment" and tested the " $a$ paths," whereas in Study 3, we manipulated the reasons connected to performance goals and tested the " $b$ paths."

In Study 1, inferring the causal nature of the link between selective assessment and controlled reasons is especially challenging. In CMS, assessment clearly serves a selective function (identifying the students who qualify for university), but is not explicitly based on relative performance. Note that rarely do institutions openly admit ranking students, although most of the students from programs using selective assessment perceive "hidden" numerus clausus (e.g., medical students; Sommet et al. 2013, Study 2). Be that as it may, the effect of the preparatory program on controlled reasons in Study 1 could have been driven equally by selection (absent from Polymath) or by a mere external evaluation (e.g., based on absolute performance; also absent from Polymath). In Study 2, three conditions were therefore compared: Participants performed a test that was presented as a self-assessment (no external evaluation, no selection), evaluative assessment (external evaluation, no selection), or selective assessment (external evaluation, selection). Performance-goals were expected to be regulated by more controlled reasons in the last condition since it is the only condition to create an external incentive to outperform others.

\section{Study 2: inducing selective assessment}

Study 2 aimed to test Sub-Hypothesis 1, while experimentally manipulating the type of assessment (the " $a 1$ path" in Study 1). Students were presented with an intelligence test that was either presented as a self-, evaluative, or selective assessment. Then, they reported their achievement goals as well as the reasons connected to them. Performance goals were expected to be regulated by more controlled reasons when the test was presented as selective.

\section{Method}

\section{Participants}

A total of 216 students from a French-speaking Swiss university performed our online experimental task. Twentyeight participants, who failed the instructional manipulation check (cf. Procedure), as well as one deviant observation, were excluded from the analysis. ${ }^{3}$ The final sample consisted of $N=187$ students, 113 women and 61 men (13 missing), $M_{\text {age }}=24.78(S D=6.85)$.

\section{Procedure}

Participants received an invitation message on their student email box and the online experiment was presented as the validation of a short-form of the Raven's Progressive Matrices test.

\section{Manipulation of the type of assessment}

The experimental manipulation of the type of assessment was adapted from Sommet et al. (2013, Study 3). Participants were randomly assigned to one of three conditions:

(i) In the self-assessment condition, the test was presented as a self-assessment tool $(n=69)$. Participants read that the "purpose of the test is for each participant to self-assess his/her intelligence." Specifically, participants were told that they would be provided with the correct answers and the satisfactory response times at the end of the experiment. Thanks to this information, each of them could evaluate his/ her intelligence.

(ii) In the evaluative assessment condition, the test was presented as an evaluative assessment tool $(n=59)$. Participants read that the "purpose of the test is to evaluate participants on the basis of their intelligence." Specifically, participants were told that their performance at the test would be scored using their number of correct answers and response times. To complete the test, participants had to obtain a passing grade of 85/100.

(iii) In the selective assessment condition, the test was presented as a selective assessment tool $(n=59)$. Participants read that the "purpose of the test is to

\footnotetext{
3 The observation was both a statistical outlier (studentized deleted residuals above 4) and an influential case (Cooks' Ds $>0.1$ ) on several outcome variables. However, if the participant had not been excluded, the hypothesized interaction between the planned contrast and performance goals would have remained significant, $B=0.26 \mathrm{CI}$ [0.04, 0.48], $p=.020, \eta_{\mathrm{p}}^{2}=.03$.
} 
select the best participants on the basis of their intelligence." Specifically, participants were told that they would be ranked according to their number of correct answers and response times. To be selected, participants had to place themselves among the top $15 \%$ of participants.

Participants did not significantly differ on sex and age across conditions (see Supplementary Materials, middle part of Table S1). The complete instructions are reported in Supplementary Materials.

\section{Raven's test and instructional manipulation check}

Following the induction, achievement goals and reasons connected to achievement goals were measured. This time, items were task-specific, with participants having to report their goals and reasons in anticipation of the test. Then, participants took a 10-matrix version of the Raven's test. Once the test completed, they were asked to share three responses with another alleged student $(M=3.33$ responses shared, $S D=1.57)$. Before the debriefing, participants were asked to recall the purpose of the test: "self-assessing one's intelligence," "obtaining a score greater than 85/100," or "being in the top $15 \%$ of participants." As mentioned previously, the participants whose answer did not correspond to their condition were excluded.

\section{Variables}

Table 1 presents the descriptive statistics and correlation matrix.

\section{Strength of achievement goals}

We adapted the items from the same questionnaire as in Study 1. A sample item for performance goals is "It is important for me to do better at the test than other students." A sample item for mastery goals is "I want to learn as much as possible from the exercise."

\section{Reasons connected to achievement goals}

We adapted the items from the same questionnaire as in Study 1 . This time, reasons connected to mastery goals were also measured. To put it plainly, we measured (i) autonomous and (ii) controlled reasons connected to performance goals, as well as (iii) autonomous and (iv) controlled reasons connected to mastery goals.

\section{Results}

\section{Preliminary analysis}

In a preliminary analysis, performance goals were regressed on the type of assessment (selective assessment vs. evaluative assessment vs. self-assessment condition). Inconsistent with prior research, performance goals did not differ as a function of the type of assessment, $F(2,184)=0.83$, $p=.436$. As in Study 1, we did not aim at testing the effect of preparatory program on the strength of performance goals, but on the reasons connected with performance goals, and this result will not be commented.

\section{Main analysis}

Table 3 presents the full set of results.

\section{Overview of the contrast analysis}

A specific hypothesis was formulated: The effect of performance goals was expected to be stronger in the selective assessment condition than in the evaluative assessment and self-assessment conditions. Such a specific hypothesis could not be tested appropriately using a two degree-of-freedom omnibus test and, instead, the type of assessment was broken down into two contrasts (Rosnow and Rosenthal 1991). We designed a planned contrast whereby the selective assessment condition was compared to the self-assessment and evaluative assessment conditions (respective weights were: $+2 / 3,-1 / 3,-1 / 3$ ), as well as an orthogonal contrast comparing the self-assessment and evaluative assessment conditions (respective weights were: $0,-1 / 2,1 / 2$ ). Four models were built, using autonomous or controlled reasons connected to performance or mastery goals as the outcome. For each model, the reasons were regressed on mean-centered performance goals, mean-centered mastery goals, the planned contrast, the orthogonal contrast, and all the possible interactions. Two conditions had to be met for the null hypothesis to be rejected (Judd et al. 2015): (i) a significant performance goals $\times$ planned contrast interaction (a stronger effect of performance goals in the selective assessment condition), and (ii) a non-significant performance goals $\times$ orthogonal contrast (ensuring that there was no difference between the effects of performance goals in the self-assessment vs. the evaluative assessment conditions).

\section{Controlled reasons connected to performance goals}

In line with Study 1's results and consistent with SubHypothesis 1, the interaction between the planned contrast and performance goals was significant, $B=0.26[0.04$, 0.48], $p=.020, \eta_{\mathrm{p}}^{2}=.03$. Simple slope analysis revealed 


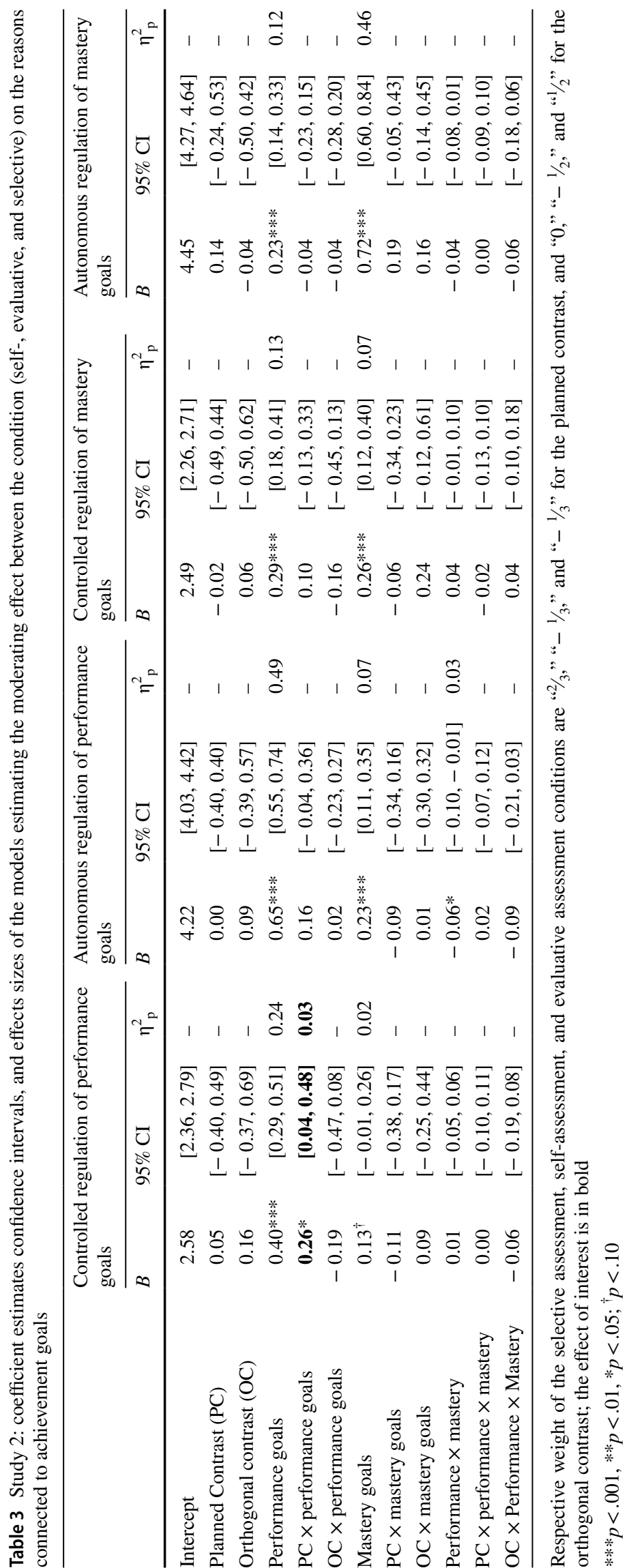




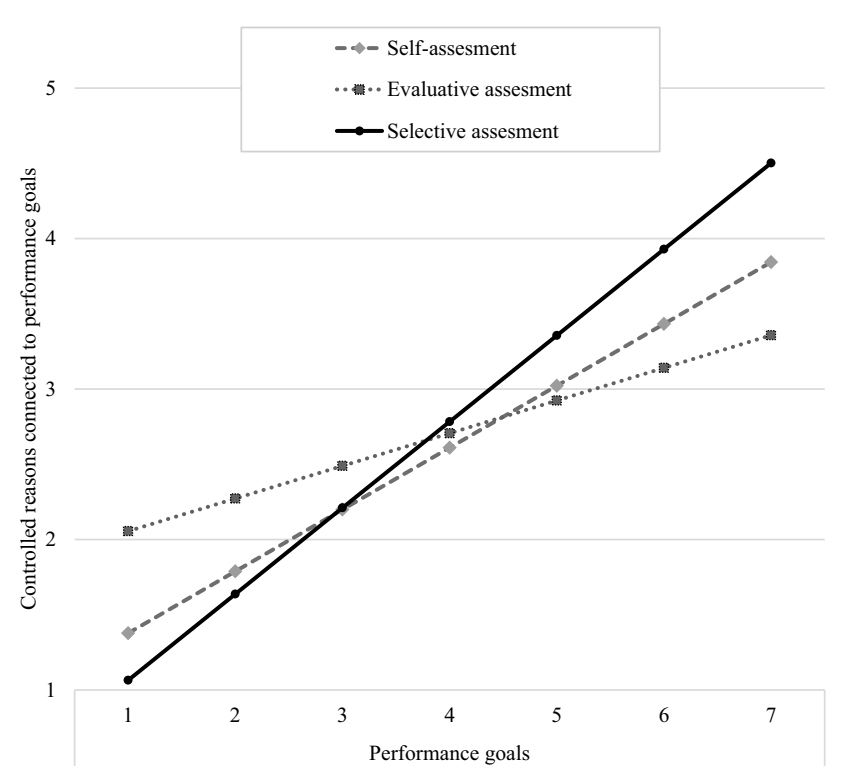

Fig. 4 Study 2: association between performance goals and controlled regulation, as a function of the experimental condition

that performance goals were regulated by more controlled reasons in the selective assessment condition, $B=0.57[0.40$, $0.74], p<.001, \eta_{\mathrm{p}}^{2}=.10$, than in the self- assessment condition, $B=0.41[0.23,0.59], p<.001, \eta_{\mathrm{p}}^{2}=.10$, and the evaluative assessment condition, $B=0.22$ [0.01, 0.42], $p=.039$, $\eta_{p}^{2}=.02$ (Fig. 4). The interaction between the orthogonal contrast and performance goals was not significant, $B=-0.19[-0.47,0.08], p=.166$, indicating that the effect of performance goals did not significantly differ between the self- assessment condition and the evaluative assessment condition. In this and the following model, main effects of mastery and performance goals were observed (see Table 3); as these effects were not theoretically relevant (goals and reasons are intercorrelated), they are not commented.

\section{Autonomous reasons connected to performance goals}

An interaction between performance and mastery goals was observed, $B=-0.06[-0.10,-0.01], p=.024, \eta_{p}^{2}=.03$. Specifically, performance goals were regulated by more autonomous reasons when mastery goals were low ( $-1 \mathrm{SD})$, $B=0.75[0.60,0.89], p<.001, \eta_{\mathrm{p}}^{2}=.37$, than high (+1 SD), $B=0.55[0.43,0.66], p<.001, \eta_{\mathrm{p}}^{2}=.34$ (for a graphical representation of the interaction, see Supplementary Materials, Figure S1). No relevant effects were observed.

\section{Controlled reasons connected to mastery goals}

No relevant effects were observed.

\section{Autonomous reasons connected to mastery goals}

No relevant effects were observed.

\section{Additional analysis}

One could have expected an interaction between the planned contrast and performance goals in predicting the number of responses to the Raven's test shared with the so-called other. To test for this interaction, we regressed the number of responses shared on the same predictors as before. The interaction was not significantly different from zero, $B=-0.03[-0.29,0.23] p=.820$. As the present procedure had not been used before in the literature, it was difficult to determine whether the null hypothesis was indeed true, or if it was a type II error due to improper material. Hence, variables measured after the Raven's test were not considered.

\section{Discussion}

Consistent with Sub-Hypothesis 1 and conceptually replicating Study 1, performance goals were regulated by more controlled reasons when the test was presented as a selective assessment than as a self- or evaluative assessment tool. Importantly, selective assessment rather than merely evaluative assessment was the key variable predicting the controlled nature of the reasons connected to performance goals. These findings were specific to performance goals (mastery goals did not interact with the condition in predicting reason outcomes) and controlled reasons connected to performance goals (in particular, performance goals did not interact with the condition in predicting controlled reasons connected to mastery goals).

A third study aimed to finish "unpacking" the mediated moderation model. We manipulated the mediating variable, namely the reasons connected to performance goals, while keeping constant the other predictors. Importantly, in Study 2 , the additional results pertaining to information sharing were inconclusive, which may be due to the fact that we used a procedure that had not been used before in the literature. Thus, in Study 3, we decided to use an experimental paradigm widely used in research on performance goals and information sharing behavior, namely the Winter Survival Exercise (e.g., Poortvliet 2012; Poortvliet et al. 2007, 2009a).

\section{Study 3: Inducing reasons connected to performance goals}

Study 3 aimed to test Sub-Hypothesis 2, while experimentally manipulating the reasons connected to performance goals (the " $b 1$ path" in Study 1). Depending on the condition, 
autonomous or controlled reasons connected to performance goals were induced. Then, participants had to solve an exercise and share their responses with another fictitious participant. Controlled reasons connected to performance goals were expected to be a positive predictor of exploitation orientation and a negative predictor of information sharing behavior.

\section{Method}

\section{Participants}

A total of 255 Amazon Mechanical Turk workers (MTurkers) took part in the experiment. Twenty-eight participants were excluded due to missing data. Six participants who refused to give their consent following the autonomous reasons induction, as well as 29 others who gave an incoherent preliminary ranking, were also excluded (cf. Procedure). The final sample consisted of $N=192$ MTurkers, 98 women and 94 men, $M_{\text {age }}=29.51(S D=9.14)$.

\section{Procedure}

Participant were recruited using MTurk. They received USD 0.50 for participating. To reduce the number of nonnaïve workers, only those having $<50$ approved HITs were allowed to participate. The online experiment was presented as a research on "reasoning ability of individuals." Participants were told that they would have to solve a problem and share their solution with another participant.

\section{Preliminary ranking}

The task was broadly similar to Poortvliet et al. (2007). Participants performed the so-called Winter Survival Exercise (for the complete material, see Johnson and Johnson 1980, p. 56). The task consisted in reading a scenario describing a crash landing in a wilderness area on a cold winter's day. Surviving passengers had managed to salvage fifteen items (e.g., a knife, 30 feet of rope, two ski poles) and participants were asked to rank these items in order of importance to stay alive. They were told to start with $1=$ the most important and to proceed to $15=$ the least important. As mentioned previously, participants whose sum of ranks was erroneous, that is, differing from $15+14+13+\ldots+1=120$, were excluded. In addition to the ranking, participants had to provide brief rationale for each decision $(M=4.58$ words per decision, $S D=3.46$ ).

\section{Manipulation of the reasons connected to performance goals}

Following the preliminary ranking, participants were paired with a bogus other who had purportedly carried out the same assignment. They were told that they would have to share their answers with him/her, and that s/he would eventually do the same. At this point, all participants were told that their goal was "to perform better on the final ranking as compared to the other's ranking" (the performance-goal induction used in Poortvliet et al. 2007). Then, participants were randomly assigned to one of two conditions:

(i) In the autonomous reasons condition $(n=99)$, participants were told that the choice to adopt performance goals was theirs. They had to tick a live button to indicate that they fully and freely consented to do so. These instructions were adapted from Spray et al. (2006). As in this research, and as mentioned previously, participants who did not give their consent were excluded.

(ii) In the controlled reasons condition $(n=93)$, participants were required to adopt performance goals. We used a controlling communication style, that is, a prescriptive language with words as "must," "should," or "have to." These instructions were adapted from Crouzevialle and Butera (2013).

Participants did not significantly differ on sex and age across condition (see Supplementary Material, lower part of Table S1). The complete instructions are reported in Supplementary Materials.

\section{Ranking sent to the bogus other}

Following the induction, participants were asked to "give the ranking of the items (starting from ' 1 ' for the most important and proceeding to ' 15 ' for the least important) [that they] would like to send to the other participant." Participants were also asked to provide "a reason for each decision" $(M=4.17$ words per decision, $S D=3.41)$. Participants were not explicitly told that they could modify their ranking to deceive the other. Once the ranking was sent, participants expected to receive "the answers of the other participant." Before the debriefing, participants did receive the other's ranking and made their final ranking. However, as we are interested in openness in information giving rather than in the utilization of received information, this variable was not treated.

\section{Variables}

\section{Exploitation orientation}

We used the same questionnaire as in Study $1(\alpha=.86$, $M=2.40, S D=1.31$ ). 
Fig. 5 Study 3: indirect effects of the reasons connected to achievement goals-via exploitation orientation-on information sharing behavior (upper panel) and on the number of words per decision shared with the bogus other (lower panel). Notes: numbers in brackets represent $95 \%$ confidence intervals: $* * * p<.001, * * p<.01, * p<.05$

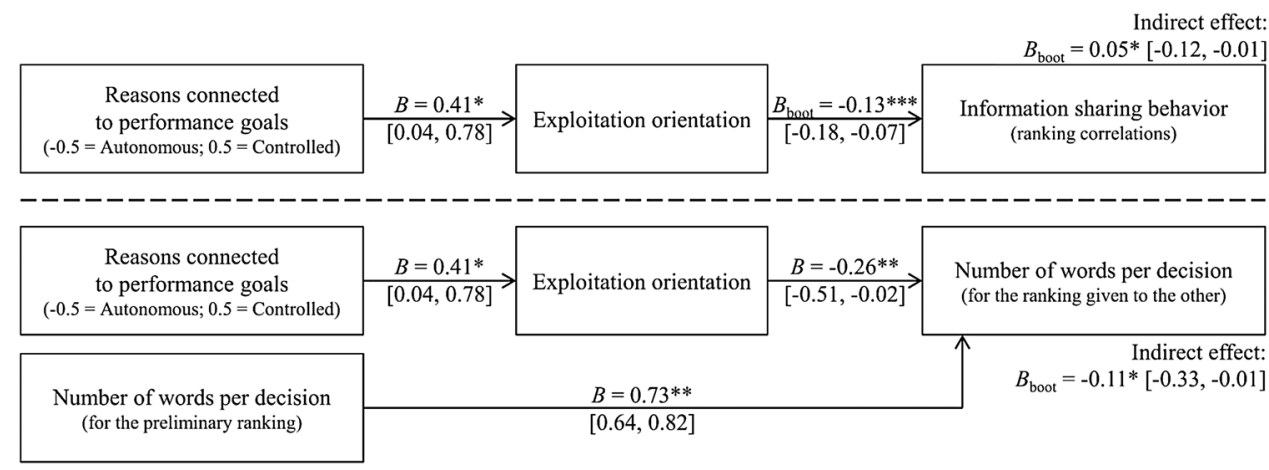

Information sharing behavior

In the exact same way as in Poortvliet et al. (2007), we computed "Spearman's rank-order correlation between the initial ranking the participants produced and the ranking they gave to the other" (p. 1440). The higher the correlation, the more the participant was open to the exchange partner. A correlation of 1 meant that s/he had given his/her answers to the other without modifying them at all. The average correlation was of $M_{\mathrm{r}}=.77 S D_{\mathrm{r}}=.34$. Note that the variable was negatively skewed, with a skewness of $s k=-3.11$ and a kurtosis of $k=13.57$.

\section{Results}

Figure 5 presents a graphical representation of the results.

\section{Overview of the regression analysis}

Two regression models were built. First, exploitation orientation was regressed on the condition $(-0.5=$ autonomous reasons and $+0.5=$ controlled reasons). Second, information sharing behavior was regressed on the same predictor. Given that ranking correlations were non-normally distributed, bootstrap resampling method was used (with 50,000 bootstrap samples; see Berkovits et al. 2000). The results are similar with or without bootstrapping.

\section{Exploitation orientation}

In line with Study 1's results and consistent with SubHypothesis 2, reasons connected to performance goals were a positive predictor, $B=0.41[0.04,0.78], p=.032, \eta_{\mathrm{p}}^{2}=.02$. Participants reported a higher exploitation orientation in the controlled reasons condition $(M=2.61[2.35,2.88])$ than in the autonomous reasons condition $(M=2.20[1.95,2.46])$.

\section{Information sharing behavior}

Contrary to Sub-Hypothesis 2, reasons connected to performance goals were not a significant predictor, $B_{\text {boot }}=0.04$ CI [- 0.06, 0.14], $p=.409$. However, an indirect effect was found: Controlled reasons connected to performance goals predicted exploitation orientation, which itself negatively predicted information sharing behavior, $B_{\text {boot }}=-0.13$ $[-0.18,-0.07], p<.001, \eta_{p}^{2}=.10$ and the negative effect of controlled reasons was transmitted on information sharing behavior through exploitation orientation, $B_{\text {boot }}=-0.05$ $[-0.12,-0.01]$ (the indirect effect was calculated in the same way as in Study 1). ${ }^{4}$

\section{Additional analysis}

As supplemental exploratory analysis, the same regression model was built, using the average number of words per item shared with the bogus other as the outcome variable. We additionally controlled for the number of words provided in the preliminary ranking. The idea was that a lower number of words shared-just as a lower ranking correlation-meant less openness to information sharing. Again, reasons connected to performance goals were not a "direct" predictor, $B=0.23$ [ $-0.42,0.88], p=.493$. However, the same indirect effect as earlier was found: Exploitation orientation was negatively associated with the number of words shared with the other, $B=-0.26[-0.51,-0.02], p=.035, \eta_{\mathrm{p}}^{2}=.02$, conveying the effect of controlled reasons connected to performance goals on the behavioral measure, $B_{\text {boot }}=-0.11$ $[-0.33,-0.01]$.

\footnotetext{
${ }^{4}$ For this analysis, five participants had to be excluded due to missing values on the ranking provided to the other participants. Despite finishing the study (i.e., providing a final ranking), these five participants did not give any answer to the bogus other. Interestingly, four of them were in the controlled reasons condition.
} 


\section{Discussion}

Consistent with Sub-Hypothesis 2 and conceptually replicating Study 1, controlled reasons connected to performance goals predicted exploitation orientation. Moreover, we found an indirect effect of controlled reasons on information sharing behavior: Controlled (vs. autonomous) reasons connected to performance goals prompted higher levels of exploitation orientation, which in turn was related to a lower openness in information sharing and less number of words exchanged.

\section{General discussion}

In the present research, we relied on the achievement goal complex framework to investigate when and why performance goals predict an exploitation orientation toward information exchange.

\section{Summary of the findings}

Study 1 tested the General Hypothesis (performance goals $\times$ selective assessment $\rightarrow$ controlled reasons $\rightarrow$ exploitation orientation) in a "real world" environment. Answering our "when" question, performance goals were a more positive predictor of exploitation orientation in a program using selective assessment (vs. a program mostly similar in content, but using self-assessment). Answering our " why" question, this was explained by the fact that performance goals were regulated by more controlled reasons in the first program.

As Study 1 was correlational, we used an experimental causal-chain-like design to test the causal nature of the key model paths. We induced the moderating and the mediating variables one after the other, testing subparts of our main hypothesis in two steps. Study 2 tested Sub-Hypothesis 1 (performance goals $\times$ selective assessment $\rightarrow$ controlled reasons), while experimentally inducing selective assessment. Consistent with our prediction, performance goals were regulated by more controlled reasons when a test was presented as a selective assessment (vs. self-evaluative or merely evaluative). Study 3 tested Sub-Hypothesis 2 (controlled reasons $\rightarrow$ exploitation orientation), while experimentally inducing controlled reasons connected to performance goals. Consistent with our prediction, controlled reasons connected to performance goals were a positive predictor of self-reported exploitation orientation, as well as an indirect predictor of information sharing behavior.

\section{Contributions}

Our work offers two interrelated contributions to the literatures on assessment policies and achievement goal complexes. It reveals how selective assessment changes both the subjective meaning and predictive utility of performance goals.

\section{Selective assessment changes the subjective meaning of performance goals}

To date, achievement goal theorists have devoted much effort to investigating the competition-related predictors of the strength of performance goals. For instance, they showed that being in a competitive classroom (Skaalvik and Federici 2016), having a competitive supervisor (Sommet et al. 2017), or working with competitive peers (Chen et al. 2017), predict the endorsement of performance goals.

Our findings suggest that selective assessment (a competition-related antecedent) is not only likely to alter the strength component of achievement motivation (a stronger inclination toward outperforming others) but also its reason component (external prods). From a theoretical perspective, this indicates that selective assessment does more than activating concerns regarding relative competence leading to the endorsement of performance goals (for a related meta-analysis, see Murayama and Elliot 2012); selective assessment creates an external incentive leading to the controlled regulation of these performance goals (see Deci and Ryan 2016).

Critical here is the conceptual distinction between antecedents, goals, and reasons. As opposed to antecedents, goals and reasons are in essence psychological and the most proximal predictors of behaviors (Fryer and Elliot 2008; Elliot and Thrash 2001; for a related discussion, see Liem and Elliot 2018). In our case, selective assessment is clearly better conceived as an antecedent, because it is neither psychological in nature nor a direct instigator of behaviors. Specifically, selective assessment should be conceived as a structural antecedent connecting performance goals to controlled reasons (the goal and the reason elements are assumed to co-occur), thereby molding a composite performance goal-reason variable: A controlled performance goal complex (outperforming others because of external prods). To our knowledge, this set of studies is the first to empirically examine the structural antecedent of an achievement goal complex. This paves the way for further investigation of this issue, as it allows both a better account of achievement motivation and-as we are about to argue- $\mathrm{a}$ better prediction of outcomes. 


\section{Selective assessment changes the predictive utility of performance goals}

There are several hints in the literature that performance goals endorsed in a controlling environment are more detrimental for achievement-related outcomes. For instance, performance goals induced in an autonomy-suppressive context were found to predict a lower persistence than performance goals induced in an autonomy-supportive context (Spray et al. 2006; for a partial conceptual replication, see Benita et al. 2017). Likewise, perceived performance goal structure was found to predict a lower motivation to learn when teacher autonomy support is low than when it is high (Ciani et al. 2010).

Our set of studies complements this extant research, by showing that a controlling environment (selective assessment herein) changes the predictive utility of performance goals with regards to a particular interpersonal outcome: exploitation orientation. Our findings point out that performance goals adopted in the context of selective assessment are more predictive of exploitation orientation than performance goals adopted in the context of non-selective assessment. This is attributable to the fact that performance goals are more likely to be regulated by controlled reasons when the pressure to outperform others is externally imposed (forming a controlled performance goal complex), than when the will to outperform others emanates from non-external forces (forming other types of performance goal complexes). Yet, individuals oriented toward a controlled performance goals complex are more likely to appraise impediments to goal attainment as a threat (for related research, see Delrue et al. 2016; Ntoumanis et al. 2014). Specifically, when regulated by controlled reasons, performance goals are supposedly associated with perceptions of others as obstacles to be eliminated at any cost, making individuals oriented toward a controlled performance goals complex more likely to act deceitfully, expecting to get information from others without giving them anything in return.

On a related note, our work may be compared to research on "appearance goals," which focus on demonstrating competence by outperforming others, and which can be seen as a type of controlled performance goals complex (see Senko 2016: for additional relevant research, see Hodis et al. 2016). For instance, it is plausible for appearance goals and for contexts in which selective assessment is salient to predict appearance goals (for a similar of argument, see Daumiller et al. 2018) to predict exploitation orientation (in the same way as appearance goals negatively predict performance and other adaptive educational outcomes; for relevant meta-analyses, see Hulleman et al. 2010; Senko and Dawson 2017).

\section{Limitations}

Some limitations should be acknowledged. First, in Studies $1-2$, the internal consistency of the controlled reasons connected to performance goals was rather low $(.60<\alpha \mathrm{s}<.65)$. This is because the construct was captured using only two items (to limit the length of our first questionnaire). As measurement error is likely to result in biased coefficient estimates, it would be advisable that future research use a scale with more items.

Second, in Study 3, controlled reasons connected to performance goals did not directly predict information sharing behavior, but only did so indirectly via self-reported exploitation orientation. However, there are two important factors to keep in mind. First, our prediction primarily focused on exploitation orientation rather than on information sharing behaviors. Second, whereas effects on behavioral measures are obviously harder to detect, the fact that self-reported exploitation orientation and information sharing behaviors were correlated speaks in favor of convergent validity.

Third, one can raise the question of multicollinearity (i.e., intercorrelation among predictor variables). First, according to extant research, our main predictor variable (selective assessment) and our moderating variable (performance goals) are supposedly linked (e.g., Jury et al. 2017; Sommet et al. 2015). However, it must be kept in mind that the absence of multicollinearity is not an assumption of ordinary least square method (Freud and Littell 2000). Specifically, the main problem arising from multicollinearity is the lack of information in data: In our case, in the context of selective assessment, performance goal-oriented participants might have been simply overrepresented (and vice versa). In the end, multicollinearity might have increased the risk of false negative errors, but not the risk of false positive errors (Mason and Perreault Jr 1991).

Fourth, one may question the way in which performance goals and controlled reasons were operationalized (i.e., as two separate constructs) as well as their location in the model (i.e., goals preceding reasons). Arguably, the combination between performance goals and controlled reasons forms a single, inseparable controlled performance goal complex (Sommet and Elliot 2017), which could be better assessed using single, inseparable items (e.g., Senko and Tropiano 2016). Future research may rely on this operationalization and test for a simpler model in which controlled performance goal complex mediates the relationship between selective assessment and exploitation orientation.

\section{Conclusion}

Despite the aforementioned limitations, the present research suggests that, as a function of selective and non-selective contexts, comparable performance goals may be connected 
to different reasons and lead to a different orientation toward exploitation. Broadly speaking, such a complex phenomenon stresses the importance of considering contextual antecedents, achievement goal content, and achievement goal motives, to better understand achievement motivation as well as better predict achievement-related outcomes.

\section{References}

Autin, F., Batruch, A., \& Butera, F. (2015). Social justice in education: How the function of selection in educational institutions predicts support for (non) egalitarian assessment practices. Frontiers in Psychology, 6, 707.

Benita, M., Shane, N., Elgali, O., \& Roth, G. (2017). The important role of the context in which achievement goals are adopted: An experimental test. Motivation and Emotion, 41, 180-195.

Berkovits, I., Hancock, G. R., \& Nevitt, J. (2000). Bootstrap resampling approaches for repeated measure designs: Relative robustness to sphericity and normality violations. Educational and Psychological Measurement, 60, 877-892.

Bourdieu, P., \& Passeron, J.-C. (1970). La Reproduction: Éléments d'une théorie du système d'enseignement [Reproduction: Elements for a Theory of the Educational System]. Paris: Editions de Minuit.

Chen, C. H., Law, V., \& Chen, W. Y. (2017). The effects of peer competition-based science learning game on secondary students' performance, achievement goals, and perceived ability. Interactive Learning Environments, 26(2), 235-244

Cheung, P. C., Ma, H. K., \& Shek, D. T. (1998). Conceptions of success: Their correlates with prosocial orientation and behaviour in Chinese adolescents. Journal of Adolescence, 21, 31-42.

Ciani, K. D., Middleton, M. J., Summers, J. J., \& Sheldon, K. M. (2010). Buffering against performance classroom goal structures: The importance of autonomy support and classroom community. Contemporary Educational Psychology, 35, 88-99.

Conroy, D. E., Elliot, A. J., \& Thrash, T. M. (2009). Achievement motivation. In M. R. Leary \& R. H. Hoyle (Eds.), Handbook of individual differences in social behavior (pp. 382-399). NewYork: Guilford Press.

Coombs, R. (1998). Surviving medical school. Thousand Oaks: Sage.

Crouzevialle, M., \& Butera, F. (2013). Performance-approach goals deplete working memory and impair cognitive performance. Journal of Experimental Psychology: General, 142, 666-678.

Darnon, B., \& Butera, F. (2005). Buts d'accomplissement, stratégies d'étude, et motivation intrinsèque: Présentation d'un domaine de recherche et validation française de l'échelle d'Elliot et McGregor (2001) [Achievement goals, study strategies, and intrinsic motivation: Presenting a domain of research and the French validation of Elliot \& McGregor's scale]. L'Année Psychologique, 105, 105-131.

Darnon, C., Dompnier, B., Delmas, F., Pulfrey, C., \& Butera, F. (2009). Achievement goal promotion at university: Social desirability and social utility of mastery and performance goals. Journal of Personality and Social Psychology, 96, 119-134.

Darnon, C., Dompnier, B., \& Poortvliet, P. M. (2012). Achievement goals in educational contexts: A social psychology perspective. Social and Personality Psychology Compass, 6, 760-771.

Daumiller, M., Dickhäuser, O., \& Dresel, M. (2018). University instructors' achievement goals for teaching. Journal of Educational Psychology. https://doi.org/10.1037/edu0000271.

De Paola, M. (2011). Easy grading practices and supply-demand factors: Evidence from Italy. Empirical Economics, 41, 227-246.
Deci, E. L., Betley, G., Kahle, J., Abrams, L., \& Porac, J. (1981). When trying to win: Competition and intrinsic motivation. Personality and Social Psychology Bulletin, 7, 79-83.

Deci, E. L., \& Ryan, R. M. (1985). Intrinsic motivation and self-determination in human behavior. New York: Plenum.

Deci, E. L., \& Ryan, R. M. (2000). The "what" and" why" of goal pursuits: Human needs and the self-determination of behavior. Psychological Inquiry, 11, 227-268.

Deci, E. L., \& Ryan, R. M. (2016). Optimizing students' motivation in the era of testing and pressure: A self-determination theory perspective. In W. C. Liu, J. C. K. Wang \& R. M. Ryan (Eds.), Building autonomous learners: Perspectives from research and practice using self-determination theory (pp. 9-29). Singapore: Springer Singapore.

Delrue, J., Mouratidis, A., Haerens, L., De Muynck, G. J., Aelterman, N., \& Vansteenkiste, M. (2016). Intrapersonal achievement goals and underlying reasons among long distance runners: Their relation with race experience, self-talk, and running time. Psychologica Belgica, 56, 288-310.

Elliot, A. J. (1999). Approach and avoidance motivation and achievement goals. Educational Psychologist, 34, 169-189.

Elliot, A. J., Aldhobaiban, N., Kobeisy, A., Murayama, K., Gocłowska, M. A., Lichtenfeld, S., \& Khayat, A. (2016). Linking social interdependence preferences to achievement goal adoption. Learning and Individual Differences, 50, 291-295.

Elliot, A. J., \& Church, M. A. (1997). A hierarchical model of approach and avoidance achievement motivation. Journal of Personality and Social Psychology, 72, 218-232.

Elliot, A. J., \& McGregor, H. A. (2001). A $2 * 2$ achievement goal framework. Journal of Personality and Social Psychology, 80, $501-519$.

Elliot, A. J., \& Thrash, T. M. (2001). Achievement goals and the hierarchical model of achievement motivation. Educational Psychology Review, 13, 139-156.

Freud, R. J., \& Littell, R. C. (2000). SAS system for regression. Cary: Sas Institute.

Fryer, J. W., \& Elliot, A. J. (2008). Self-regulation of achievement goal pursuit. In D. H. Schunk \& B. J. Zimmerman (Eds.), Motivation and self-regulated learning: Theory, research, and applications (pp. 53-76). New York: Lawrence Erlbaum.

Gaudreau, P. (2012). Goal self-concordance moderates the relationship between achievement goals and indicators of academic adjustment. Learning and Individual, 22(6), 827-832

Gaudreau, P., \& Braaten, A. (2016). Achievement goals and their underlying goal motivation: Does it matter why sport participants pursue their goals? Psychologica Belgica, 56, 244-268.

Gillet, N., Lafrenière, M. A. K., Huyghebaert, T., \& Fouquereau, E. (2015). Autonomous and controlled reasons underlying achievement goals: Implications for the $3 \times 2$ achievement goal model in educational and work settings. Motivation and Emotion, 39, $858-875$.

Hodis, F. A., Tait, C., Hodis, G. M., Hodis, M. A., \& Scornavacca, E. (2016). Analyzing student motivation at the confluence of achievement goals and their underlying reasons: An investigation of goal complexes. Social Psychology of Education, 19, 643-660.

Hulleman, C. S., Schrager, S. M., Bodmann, S. M., \& Harackiewicz, J. M. (2010). A meta-analytic review of achievement goal measures: Different labels for the same constructs or different constructs with similar labels? Psychological Bulletin, 136, 422-449.

Johnson, D. W., \& Johnson, R. T. (1980). Promoting constructive student-student relationships through cooperative learning. Minneapolis: Minnesota University (ERIC Document Reproduction Service No. ED 249 216). Retrived from http://files.eric.ed.gov/ fulltext/ED249216.pdf.

Johnson, D. W., Johnson, R. T., \& Smith, K. A. (2014). Cooperative learning: Improving university instruction by basing practice on 
validated theory. Journal on Excellence in University Teaching, $25,1-26$.

Judd, C. M., McClelland, G. H., \& Ryan, C. S. (2015). Data analysis: A model comparison approach (2nd edn.). New York: Routledge.

Jury, M., Darnon, C., Dompnier, B., \& Butera, F. (2017). The social utility of performance-approach goals in a selective educational environment. Social Psychology of Education, 20, 215-235.

Kaufman, N. (1994). A survey of law school grading practices. Journal of Legal Education, 44, 415-423.

Kilduff, G. J., Galinsky, A. D., Gallo, E., \& Reade, J. J. (2016). Whatever it takes to win: Rivalry increases unethical behavior. Academy of Management Journal, 59, 1508-1534.

Liem, G. A. D., \& Elliot, A. J. (2018). Sociocultural influences on achievement goal adoption and regulation: A goal complex perspective. In G. A. D. Liem \& D. M. McInerney (Eds.), Big theories revisited 2 (pp. 41-67). Charlotte: Information Age Publishing.

Liem, G. A. D., Lau, S., \& Nie, Y. (2008). The role of self-efficacy, task value, and achievement goals in predicting learning strategies, task disengagement, peer relationship, and achievement outcome. Contemporary Educational Psychology, 33, 486-512.

Mason, C. H., \& Perreault, W. D. Jr. (1991). Collinearity, power, and interpretation of multiple regression analysis. Journal of Marketing Research, 28, 268-280.

Michou, A., Matos, L., Gargurevich, R., Gumus, B., \& Herrera, D. (2016). Building on the enriched hierarchical model of achievement motivation: Autonomous and controlling reasons underlying mastery goals. Psychologica Belgica, 56, 269-287.

Murayama, K., \& Elliot, A. J. (2012). The competition-performance relation: A meta-analytic review and test of the opposing processes model of competition and performance. Psychological Bulletin, 138, 1035-1070

Nelson, R. M., \& DeBacker, T. K. (2008). Achievement motivation in adolescents: The role of peer climate and best friends. The Journal of Experimental Education, 76, 170-189.

Ntoumanis, N., Healy, L. C., Sedikides, C., Duda, J., Stewart, B., Smith, A., \& Bond, J. (2014). When the going gets tough: The "why" of goal striving matters. Journal of Personality, 82, 225-236.

OECD. (2013). Education at a Glance 2013: OECD Indicators. Paris: OECD Publishing.

Özdemir Oz, A., Lane, J. F., \& Michou, A. (2016). Autonomous and controlling reasons underlying achievement goals during task engagement: Their relation to intrinsic motivation and cheating. Educational Psychology, 36, 1160-1172.

Pekrun, R., Cusack, A., Murayama, K., Elliot, A. J., \& Thomas, K. (2014). The power of anticipated feedback: Effects on students' achievement goals and achievement emotions. Learning and Instruction, 29, 115-124.

Poortvliet, P. M. (2012). Harming others' task-related efforts: The distinct competitive effects of ranking information on performance and mastery goal individuals. Social Psychology, 44, 373-379.

Poortvliet, P. M., \& Darnon, C. (2014). Understanding positive attitudes toward helping peers: The role of mastery goals and academic self-efficacy. Self and Identity, 13, 345-363.

Poortvliet, P. M., Janssen, O., Van Yperen, N. W., \& Van de Vliert, E. (2007). Achievement goals and interpersonal behavior: How mastery and performance goals shape information exchange. Personality and Social Psychology Bulletin, 33, 1435-1447.

Poortvliet, P. M., Janssen, O., Van Yperen, N. W., \& Van de Vliert, E. (2009a). Low ranks make the difference: How achievement goals and ranking information affect cooperation intentions. Journal of Experimental Social Psychology, 45, 1144-1147.

Poortvliet, P. M., Janssen, O., Van Yperen, N. W., \& Van de Vliert, E. V. D. (2009b). The joint impact of achievement goals and performance feedback on information giving. Basic and Applied Social Psychology, 31, 197-209.
Reeve, J., \& Assor, A. (2011). Do social institutions necessarily suppress individuals' need for autonomy? The possibility of schools as autonomy promoting contexts across the globe. In R. Chirkov, R. M. Ryan \& K. Sheldon (Eds.), Human autonomy in cross-cultural context: Global perspectives on the psychology of freedom and people's well-being. New York: Springer.

Rosnow, R. L., \& Rosenthal, R. (1991). If you're looking at the cell means, you're not looking at only the interaction (unless all main effects are zero). Psychological Bulletin, 110, 574-576.

Rucker, D. D., Preacher, K. J., Tormala, Z. L., \& Petty, R. E. (2011). Mediation analysis in social psychology: Current practices and new recommendations. Social and Personality Psychology Compass, 5, 359-371.

Ryan, A. M., \& Pintrich, P. R. (1997). Should I ask for help? The role of motivation and attitudes in adolescents' help seeking in math class. Journal of Educational Psychology, 89, 329-341.

Ryan, R. M., \& Brown, K. W. (2005). Legislating competence: The motivational impact of high stakes testing as an educational reform. In C. Dweck \& A. E. Elliot (Eds.), Handbook of competence ( $p p$. New York: Guilford Press. 354 - 374).

Senko, C. (2016). Achievement goal theory: A story of early promises, eventual discords, and future possibilities. In K. Wentzel \& D. Miele (Eds.), Handbook of motivation at school (Vol. 2, pp. 75-95). New York: Routledge.

Senko, C., \& Dawson, B. (2017). Performance-approach goal effects depend on how they are defined: Meta-analytic evidence from multiple educational outcomes. Journal of Educational Psychology, 109, 574-598.

Senko, C., Hulleman, C. S., \& Harackiewicz, J. M. (2011). Achievement goal theory at the crossroads: Old controversies, current challenges, and new directions. Educational Psychologist, 46, 26-47.

Senko, C., \& Tropiano, K. L. (2016). Comparing three models of achievement goals: Goal orientations, goal standards, and goal complexes. Journal of Educational Psychology, 108, 1178-1192.

Sheldon, K. M., \& Elliot, A. J. (1998). Not all personal goals are personal: Comparing autonomous and controlled reasons for goals as predictors of effort and attainment. Personality and Social Psychology Bulletin, 24, 546-557.

Shieh, G. (2010). On the misconception of multicollinearity in detection of moderating effects: Multicollinearity is not always detrimental. Multivariate Behavioral Research, 45, 483-507.

Shin, J., Lee, Y. K., \& Seo, E. (2017). The effects of feedback on students' achievement goals: Interaction between reference of comparison and regulatory focus. Learning and Instruction, 49, 21-31.

Skaalvik, E. M., \& Federici, R. A. (2016). Relations between classroom goal structures and students' goal orientations in mathematics classes: When is a mastery goal structure adaptive? Social Psychology of Education, 19, 135-150.

Sommet, N., Darnon, C., \& Butera, F. (2015). To confirm or to conform? Performance goals as a regulator of conflict with morecompetent others. Journal of Educational Psychology, 107, 580-598.

Sommet, N., Darnon, C., Mugny, G., Quiamzade, A., Pulfrey, C., Dompnier, B., \& Butera, F. (2014). Performance goals in conflictual social interactions: Towards the distinction between two modes of relational conflict regulation. British Journal of Social Psychology, 53, 134-153.

Sommet, N., \& Elliot, A. J. (2017). Achievement goals, reasons for goal pursuit, and achievement goal complexes as predictors of beneficial outcomes: Is the influence of goals reducible to reasons? Journal of Educational Psychology, 109(8), 1141

Sommet, N., Pillaud, V., Meuleman, B., \& Butera, F. (2017). The socialization of performance goals. Contemporary Educational Psychology, 49, 337-354. 
Sommet, N., Pulfrey, C., \& Butera, F. (2013). Did my MD really go to university to learn? Detrimental effects of numerus clausus on self-efficacy, mastery goals and learning. PloS ONE, 8, e84178.

Sommet, N., Quiamzade, A., Jury, M. M., \& Mugny, G. (2015). The student-institution fit at university: Interactive effects of academic competition and social class on achievement goals. Frontiers in Psychology, 6, 769.

Spencer, S. J., Zanna, M. P., \& Fong, G. T. (2005). Establishing a causal chain: Why experiments are often more effective than mediational analyses in examining psychological processes. Journal of Personality and Social Psychology, 89, 845-851.

Spray, C. M., Wang, J. C. K., Biddle, S. J., \& Chatzisarantis, N. L. (2006). Understanding motivation in sport: An experimental test of achievement goal and self determination theories. European Journal of Sport Science, 6, 43-51.

Toma, C., Gilles, I., \& Butera, F. (2013). Strategic use of preference confirmation in group decision making: The role of competition and dissent. British Journal of Social Psychology, 52, 44-63.

Urdan, T., \& Mestas, M. (2006). The goals behind performance goals. Journal of Educational Psychology, 98, 354-365.
Vansteenkiste, M., Lens, W., Elliot, A. J., Soenens, B., \& Mouratidis, A. (2014b). Moving the achievement goal approach one step forward: Toward a systematic examination of the autonomous and controlled reasons underlying achievement goals. Educational Psychologist, 49, 153-174.

Vansteenkiste, M., Mouratidis, A., \& Lens, W. (2010a). Detaching reasons from aims: Fair play and well-being in soccer as a function of pursuing performance-approach goals for autonomous or controlling reasons. Journal of Sport \& Exercise Psychology, 32, 217-242.

Vansteenkiste, M., Mouratidis, A., Van Riet, T., \& Lens, W. (2014a). Examining correlates of game-to-game variation in volleyball players' achievement goal pursuit and underlying autonomous and controlling reasons. Journal of Sport and Exercise Psychology, 36, 131-145.

Vansteenkiste, M., Smeets, S., Soenens, B., Lens, W., Matos, L., \& Deci, E. L. (2010b). Autonomous and controlled regulation of performance-approach goals: Their relations to perfectionism and educational outcomes. Motivation and Emotion, 34, 333-353. 